\title{
Empyema in Children - Is Primary VATS the Preferred Strategy
}

\section{Rajesh Kumar Singh ${ }^{1}$, Avathi Venkatesha Gurudutta ${ }^{2}$, Supraja Chandrasekar ${ }^{3}$ and Arun Thomas ${ }^{4}$}

\author{
${ }^{1}$ Department of Paediatrics, IQ City Medical College Durgapur, West Bengal, India \\ ${ }^{2}$ Department of Paediatrics, Rangadore Memorial Hospital, Bangalore, Karnataka, India \\ ${ }^{3}$ Department of Paediatrics, Columbia Asia Hospitals, Yeshwantpur, Bangalore, Karnataka, India \\ ${ }^{4}$ Department of Paediatrics, Prakriya Hospitals, Bangalore, Karnataka, India
}

\section{Correspondence:}

Rajesh Kumar Singh

Department of Paediatrics

IQ City Medical College Durgapur,

West Bengal, India

E-mail: rrarri@yahoo.co.in

DOI: $10.3126 /$ jnps.v40i3.29534

Submitted on: $2020-06-19$

Accepted on: 2020-10-04

Acknowledgements: None

Funding: Nil

Conflict of Interest: None declared

Permission from IRB: Yes

To cite this article: Singh RK, Gurudutta $\mathrm{AV}$, Chandrasekar S. Empyema in children- is primary VATS the preferred strategy. J Nepal Paediatr Soc. 2020;40(3):197-201

\section{ABSTRACT}

Introduction: Empyema thoracis (ET) is an accumulation of pus in the pleural space. Considering the advantages of Video Assisted Thoracoscopic Surgery (VATS), including reduced length of hospitalisation, lower postoperative morbidity and mortality, VATS is the treatment of choice for cases of stage 3 empyema. The objective of this study was to study the age-sex profile, clinical presentation, etiologic agents, management and the overall treatment outcome of empyema thoracis after early VATS in children.

Methods: This was a retrospective observational study, conducted in the Department of Paediatrics, Rangadore Memorial Hospital, Bangalore, from November 2018 to March 2020. All children in the age group of 0 to 18 years diagnosed to have pyogenic empyema and presenting in stage 1 and 2 during the study period were included in the study. In the present study, 15 children were found to be having empyema (stage 1 and 2).

Results: Majority of patients $(66.6 \%)$ were seen in the age group of one to five years. Fever (100\%), breathlessness $(66.66 \%)$, and cough $(80 \%)$ were the commonest presenting features. Bacteriological isolation was possible only in three cases $(20 \%)$. Patients were treated with antibiotics and primary VATS in majority of cases $(55.33 \%)$. Average duration of hospital stay in VATS group was 12.11 days.

Conclusions: Empyema thoracis mainly affects younger children. Common presenting features are fever, difficulty in breathing and cough. Appropriate antibiotics and early VATS may be acceptable modality for management of pyogenic empyema thoracis in children.

Keywords: Empyema thoracis; Pleural fluid cytology; Video Assited Thoracoscopic Surgery

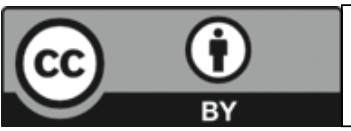

This work is licensed under creative common attribution 3.0 license 


\section{INTRODUCTION}

Empyema thoracis (ET) is an accumulation of pus in the pleural space. Empyema was described by Hippocrates in 600 B.C. as collection of pus in the pleural cavity and advocated open drainage as its treatment. ${ }^{1}$ It is a common condition in childhood having significant morbidity and mortality. 2,3 The clinical manifestations of empyema are high grade fever with chills and rigors, cough, breathlessness, chest pain. Traditionally, three stages of ET (exudative, fibrinopurulent and organisational) are defined, which are not individually distinct, but rather a progressive spectrum of clinical, biochemical and radiological features. ${ }^{4}$

There are a number of treatment modalities available for treatment of ET ranging from antibiotic treatment, intra-pleural fibrinolytic therapy (IFT) with radiologically placed pigtail catheters or a tube thoracostomy. These modalities are particularly useful for patients in early stages of empyema. For more advanced stages, surgical intervention can be performed using minimally invasive techniques including video-assisted thoracic surgery (VATS) or an open thoracotomy. ${ }^{5}$

There is little divergence on management of stage 1 and stage 3 pleural disease. Controversies have existed around management of stage 2 disease. Several trials have examined both IFT and VATS as a treatment modality and have concluded that both have similar results. ${ }^{6-8}$ Recently, VATS, pleural adhesiolysis, debridement, irrigation and decortication have also been proven to serve as an effective treatment modality in the early stages of empyema, especially during the stage II fibrinopurulent stage..$^{5,9-11}$ The main aim was to study the epidemiological aspects of the disease, etiological agents, clinical features and associated lesions in diagnosis of empyema and the outcome of early VATS on morbidity of disease in children.

\section{METHODS}

This was a retrospective study, conducted at Rangadore Memorial Hospital Bangalore, India, from November 2018 to March 2020. The study was approved by the Institute's Ethical Committee. All children in the age group of 0 to 18 years diagnosed pyogenic empyema during the study period were included in the present study. A detailed history was taken regarding presenting complaints, immunisations etc. Detailed general and systemic examination was done. Routine and relevant specific examinations were done. These included haemoglobin estimation, total leukocyte count, ESR and HIV. All patients suspected of pleural effusion clinically were subjected to chest $\mathrm{X}$-ray, USG and (if required) CT thorax. The diagnostic criteria for ET was presence of pleural effusion on clinical and radiological examination and aspiration of pus from the thoracic cavity. In cases where there was clear evidence of pleural disease with loculated empyema with septations, VATS was performed as a primary procedure. On the other hand, in cases with clear exudative fluid, ICD placement was done under USG guidance at the first instance. Immediately after the ICD placement, a CXR was performed to see the position of the ICD. After 24 hours, clinical assessment of empyema resolution was done on the basis of resolution of fever, respiratory distress, and general well being of the patients. In addition to that, a series of follow-up CXR were taken at three, five and seven days, according to need. Pleural fluid was studied for gram staining, microscopy, cytology, biochemical analysis including protein estimation, pleural culture and antibiotic sensitivity pattern. Children showing evidence of further deterioration with worsening inflammatory markers and persistent high grade fever 48 hours after ICD insertion were considered for VATS.

\section{RESULTS}

Out of the total 2404 cases admitted in the Paediatrics department, $15(0.62 \%)$ cases were having empyema. Baseline demographic characteristics of patients are shown in Table 1. The incidence of empyema was more common $66.66 \%$ (Eight cases) in one to five years age group and $6.66 \%$ (One case) in less than one year and 20\% (Three cases) in five to ten years and $6.66 \%$ (One case) in children more than 10 years. In the present study female children were more affected $60 \%$ (Nine cases) than male children $40 \%$ (Six cases).

In the present study only $6.66 \%$ (one child) was severely malnourished (weight / age $<-3 \mathrm{SD}$ ). Fever, cough, breathlessness were the commonest symptoms. Mean duration of fever at the time of admission was five $( \pm 3.3)$ days. Out of 15 cases, nine $(60 \%)$ were having empyema on right side and five $(33.33 \%)$ cases were having empyema on left 
Table 1. Base line Characteristics of patients

\begin{tabular}{|c|c|c|c|}
\hline Characteristic & & No & Percentage \\
\hline \multirow[t]{2}{*}{ Sex } & Male & 6 & $40 \%$ \\
\hline & Female & 9 & $60 \%$ \\
\hline \multirow[t]{4}{*}{ Age } & $<1 \mathrm{yr}$ & 1 & $6.66 \%$ \\
\hline & $1-5 \mathrm{yr}$ & 10 & $66.66 \%$ \\
\hline & $5-10 y r$ & 3 & $20 \%$ \\
\hline & $>10 \mathrm{yr}$ & 1 & $6.66 \%$ \\
\hline \multirow[t]{4}{*}{ Symptoms } & Fever & 15 & $100 \%$ \\
\hline & Cough & 12 & $80 \%$ \\
\hline & Breathlessness & 10 & $66.66 \%$ \\
\hline & Pain chest & 4 & $26.66 \%$ \\
\hline \multirow{3}{*}{$\begin{array}{l}\text { Side of } \\
\text { accumulation } \\
\text { of empyema }\end{array}$} & Right & 9 & $60 \%$ \\
\hline & Left & 5 & $33.33 \%$ \\
\hline & Bilateral & 1 & $6.66 \%$ \\
\hline \multirow[t]{3}{*}{$\begin{array}{l}\text { Size of effusion } \\
\text { on chest } \\
\text { radiograph }\end{array}$} & $\begin{array}{l}\text { Small } \\
(<1 / 4 \mathrm{CXR} \\
\text { opacified })\end{array}$ & 10 & $66.66 \%$ \\
\hline & $\begin{array}{l}\text { Moderate } \\
(<1 / 2 \text { CXR } \\
\text { opacified })\end{array}$ & 4 & $26.66 \%$ \\
\hline & $\begin{array}{l}\text { Large } \\
(>1 / 2 \mathrm{CXR} \\
\text { opacified })\end{array}$ & 1 & $6.66 \%$ \\
\hline
\end{tabular}

side. Out of 15 cases blood culture was positive only in $20 \%(\mathrm{n}=3)$ cases. Staphylococcus aureus was grown in one case and streptococcus pneumoniae was grown in two cases. Pus cultures of pleural fluid failed to grow any organism in any of the patients. Out of 15 cases massive pleural effusion in chest X-ray was seen only in $6.66 \%$ (One case). Only four out of 15 patients required $\mathrm{CT}$ chest for diagnosis.

Table 2 depicts the outcome of cases. Regarding the mode of treatment of empyema, $55.33 \%(n=8)$ cases were treated by primary VATS with antibiotics and $20 \%(\mathrm{n}=3)$ cases were treated by ICD drainage with antibiotics. For two children due to failure of initial treatment, VATS was done. Two children were discharged against medical advice.

Out of 13 cases managed, there were no deaths. Among the patients treated by primary VATS
Table 2. A comparison between both groups regarding outcome

\begin{tabular}{|lrrr|}
\hline \multicolumn{1}{|c}{$\begin{array}{c}\text { Mode of } \\
\text { treatment }\end{array}$} & $\begin{array}{c}\text { No of } \\
\text { Cases }\end{array}$ & \multicolumn{1}{c}{$\%$} & \multicolumn{1}{c|}{$\begin{array}{c}\text { Days of } \\
\text { hospitalization } \\
\text { (mean) }\end{array}$} \\
\hline $\begin{array}{l}\text { Primary VATS } \\
\begin{array}{l}\text { Conservative } \\
\text { (Only }\end{array}\end{array}$ & 1 & 6.66 & 12.11 \\
antibiotics) & 2 & 20 & 17.5 \\
$\begin{array}{l}\text { ICD } \\
\begin{array}{l}\text { ICD followed } \\
\text { by VATS }\end{array}\end{array}$ & 1 & 6.66 & 12 \\
$\begin{array}{l}\text { Conservative } \\
\text { followed by }\end{array}$ & 1 & 6.66 & 17 \\
VATS & & & \\
\hline
\end{tabular}

average duration of hospital stay was 12.11 days. On an average, children became afebrile after 4.75 days of primary VATS. Three patients were treated by ICD and antibiotics, out of which one required late VATS due to poor response.

\section{DISCUSSION}

Incidence of ET was $0.62 \%$ in our study population. Complicated parapneumonic effusions are appearing more frequently by most accounts, with reported increase in incidence rates in both Europe and the United States. ${ }^{2,3}$ In England, the rate of admission with a diagnosis of empyema increased over the last decade, most notably in children aged one to four years. ${ }^{12}$ Majority of patients in our study were under-five. A recent study by Rao et al, conducted in a similar setting of tertiary hospital in South India showed similar results in relation to age distribution. ${ }^{13}$ We observed female to male ratio to be 3:2 which was similar to other studies. ${ }^{12,14}$ Fever, breathlessness and cough were the most common manifestations found at admission in our study cohort similar to many other studies. ${ }^{14,15}$ In our study blood culture was positive in $20 \%$ of cases which is comparable to other studies. ${ }^{6}$ Most children in our study received oral antibiotics prior to presentation and this could be a contributing factor to the lower rate of pathogen detection. Culture positivity rates are generally low in children with community acquired pneumonia (CAP) without other comorbidities ${ }^{7,16}$ In a large multi-center study, prevalence of bacteremia was as low as $2.2 \%$ in uncomplicated CAP and $6.4 \%$ 
among patients with severe or complicated pneumonia. However, this is likely to be an underestimate as many children in this study did not have blood cultures obtained and rate of bacteraemia were two fold higher in children with empyema. Therefore, blood culture remains an important investigation despite its low yield. ${ }^{17}$

There are a number of studies comparing the different modes of treatment available. These studies have compared days of hospital stay, number of days child was febrile post procedure, days of post procedure hospital stay or the total cost of treatment to the patient. In our study, most of the patients were treated by VATS and compared to ICD group the duration of stay was lesser for VATS but this was not statistically significant $(p>0.05)$. Only one child who was treated conservatively had mild effusion and responded earlier than VATS group, which probably was due to mild nature of disease in the patient. In our study, duration of hospital stay was 12.11 days in VATS group. Various studies have shown hospital stays of approximately 10 days for children after primary VATS which is significantly lesser than other common modalities of treatment. ${ }^{10,18}$ Although present study and the others suggest better outcomes of primary VATS, one has to consider factors like availability of expertise, technical support and the cost of the procedure. Studies comparing cost of VATS versus others have shown conflicting results. While some studies have found that VATS substantially increases the cost of treatment while others have concluded that it decreases the total number of days of admission, hence reduces the cost. ${ }^{6,11}$ Main limitation of our study is the low number of cases and at the most this study can give an indication toward noninferiority of VATS. With availability of surgical expertise, VATS is the preferred initial option at our centre and we have found satisfactory results and better patient satisfaction, however the acceptable initial treatment option may be conservative approach with chest tube and / or fibrinolysis at resource constrained setup. Probably final choice of the procedure depends on multiple factors and the best course should be individualised after discussing with the parents.

\section{CONCLUSIONS}

Our study showed that incidence of ET in paediatric admissions was $0.62 \%$ and that right sided empyema was more common. Isolation of etiological agent is difficult in most of the cases. The mean average length of hospital stay was comparable between those children who underwent primary VATS versus other modes of treatment. A study with larger sample size and comparing other significant issues like cost of treatment, time taken for resolution of patient symptoms, expertise available, which are involved in empyema management is required to have a clear view on best treatment option in various clinical scenarios.

\section{REFERENCES}

1. Adams F. The genuine works of Hippocrates, Baltimore: William and Wilkins Company; 1939; 51-2.

2. Roxburg CSD, Young Son GG, Towend JA. Trends in pneumonia and empyema in Scottish children in the past 25 years. Arch Dis Child. 2008;93:316-8. DOI: https://dx.doi.org/10.1136/adc.2007.126540.

3. Bender JM, Ampofo K, Sheng X, Pavia AT, Cannon-Albright L, Byington CL. Parapneumonic empyema deaths during past century. Utah Emerg Infect Dis. 2009;15(1):44-8. DOI: 10.3201/eid1501.080618.

4. Narayanappa D, Rashmi N, Prasad NA, Kumar A. Clinico-bacteriological profile and outcome of empyema. Indian Pediatr 2013;50:783-5. PMID:23502667.

5. Wozniak CJ, Paull DE, Moezzi JE, Scott RP, Anstadt MP, York VV et al. Choice of first intervention is related to outcomes in the management of empyema. Ann Thorac Surg. 2009;87:1525-30. DOI: https://doi:10.1016/ j.athoracsur.2009.01.028.

6. Sonnappa S, Cohen G, Owens CM, Doom CV, Cairns J, Martin SS, et al. Comparison of Urokinase and Videoassisted Thoracoscopic Surgery for Treatment of Childhood Empyema. Am J Respir Crit Care Med. 2006;174: 221-7. DOI: https://doi.org/10.1164/rccm.200601-027OC. 
7. Marhuenda C, Barceló C, Fuentes I. Urokinase versus VATS for treatment of empyema: a randomised multicenter clinical trial. Pediatrics. 2014;134(5):1301-7. DOI: https://doi.org/10.1542/peds.2013-3935.

8. Peter SDS, Tsao K, Harrison C. Thoracoscopic decortication vs tube thoracostomy with fibrinolysis for empyema in children: a prospective, randomised trial. J. Pediatr. Surg. 2009;44(1):106-111. DOI:10.1016/j.jpedsurg. 2008.10.018.

9. Tong BC, Hanna J, Toloza EM, Onaitis MW, D'Amico TA, Harpole DH, et al. Outcomes of video assisted thoracoscopic decortication. Ann Thorac Surg. 2010;89:220-5. DOI:https://doi.org/10.1016/j.athoracsur. 2009.09.021.

10. Jadhav P, Raut S, Kashyap MK, Bora RA. Surgical strategy of empyema thoracis in children: open thoracotomy v/s video assisted thoracoscopy Int Surg J. 2018;5(12):3823-5. DOI: http://dx.doi.org/ 10.18203/2349-2902.isj20184741.

11. Elsayed HH, Mostafa A, Fathy E. Thoracoscopic management of early stages of empyema: is this the golden standard? J Vis Surg. 2018;4:114. DOI: http://dx.doi.org/10.21037/jovs.2018.05.18.

12. Estham KM, Freeman R, Kearns KM, Eltringham G, Clark J, Leeming J. Clinical features, aetiology of empyema in children in the North East of England. Thorax. 2004;59:522-5. DOI: 10.1136/thx.2003.016105.

13. Rao MSP, Chandra PS. A study of pediatric empyema thoracis presentation in a tertiary care hospital in Visakhapatnam, India. Int J Contemp Pediatr. 2018;5:572-5. DOI: http://dx.doi.org/ 10.18203/2349-3291.ijcp20180557.

14. Zel SK, Kazeza A, Kilic M, Koseogullaric AA, Yelmaza, Aygun AD. Conservative treatment of post parapneumonic thoracic empyema in children. Surg Today. 2004;34(12):1002-5. DOI: https://doi.org/10.1007/s00595-004-2859-5.

15. Singh V. IAP Textbook of Paediatrics. 5th edn. Jaypee Publishers; 2013:478-80.

16. Davis TR, Evans HR, Murtas J, Weisman A, Francis JL, Khan A. Utility of blood cultures in children admitted to hospital with community acquired pneumonia. J Paediatr Child Health. 2016;53(3):232-6. DOI: https://doi.org/ $10.1111 /$ jpc. 13376 .

17. Lipsett SC, Hall M, Ambroggio L, Desai S, Shah SS, Brogan TV et al. Predictors of Bacteremia in Children Hospitalized With Community-Acquired Pneumonia. Hospital Pediatrics. 2019;9(10):770-8. DOI:https://doi.org/ 10.1542/hpeds.2019-0149.

18. Scarci M, Zahid I, Billé A, Routledge T. Is video-assisted thoracoscopic surgery the best treatment for paediatric pleural empyema? Interact Cardiovasc Thorac Surg. 2011;13(1):70-6.DOI: https://doi.org/10.1510/icvts. 2010.254698 . 